This report was prepared as an account of work sponsored by the United States Government. Neither the United States nor the United States Atomic Energy Commission, nor any of their employees, nor any of their contractors, subcontractors, or their employees, makes any warranty, express or implied, or asumes any legal liability or responsibility for the accuracy, com. pleteress or usefulness of any information, apparatus, product or process disclosed, or represents that its use would not infringe privately owned rights.

In the interest of prompt tistribution, this LAMS re. port was not edited by the Technical Information statf.

Printed in the United States of America. Available trom National Technical Information Service

U. S. Department of Commerce 5285 Port Royal Road

Springfield, Virginia 22151

Price: Printed Copy $\$ 4.00$; Microfiche $\$ 1.45$ 
LA.5444-MS

Informal Report

UC. 20

ISSUED: Octuber 1973

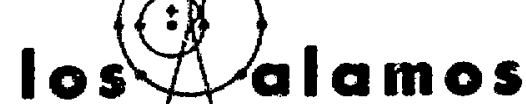

sclentite laboratory

of the Universily of Ealifornia

lOS AlAmOS. NEW MExico ors44

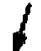

1

\section{Symmetry of Laser Driven Implosions}

by

D. B. Henderson

R. L. Marse

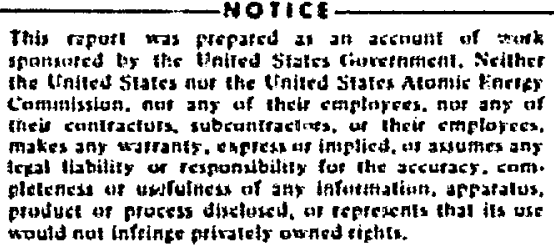

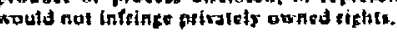


SYMETRY OF LASER DRIVEN DAPLOSIONS

by

D. B. Henderson and R. L. Morse

ABSTRACT

The echlevement of signiflcant nuclear encrgy ylelds frow leser heated pellets of thermonuclear fuel requites thet the fuel be ccopressed to at least several orders of agnitude bove intitial density. Such compresstons can be attalned by spherlcal ioplosfona, but because of the large compresaton ratios required, these Implosions wat be highly ayvertical. Celculetions of the behavior of imploding spheres and ahells by sphericel harwonte perturbaston method, and by tro dimensional hydrodynate codes utthin thetr liatcastone, have shom the lwortance of electron therat conduction in the law denatey ablaston cloud of a peliet in beinging ebout the required ywotry. These colculetions shou that at early tome in the heating of a pellet when the obletion cloud is relatively swoll and cold, the symetry requirements are most severe and cell for as miny an four leser beams. However, symetry requitements at later efmes. When most of the leser energy unst be deposited, moy be ect by as feu ss ane teas.

\section{Iftroovertow}

It hes been shown by one-dimensionst. sphericolly symetric numerical stwletions thet spheres 1.2 or she $11 \mathrm{~s}^{2}$ of chermonucleer fuel hested by toser pulses with as litele es ane kito-joule of ebsorbed energy my return more than this amount of nucleat fuston energy if the lsser pulse caspresses the fuel to $10^{3}$ or $10^{4}$ elwes soild density. These lerge compreseton rotlo tre de to ocur by taing the deposteton of laser energy onto the outatde of the sphertcel pellet of fuel in such way es to cause suffletent abletion preasure to drtue strong spherIcal teptosion. Electron theranl conduction is the process by which wost of the absorbed leser energy 1) traneported frow neer the critcal aurface in the ableted or "bla off" region, wheze it te ebsorbed, to the surface of the high denstty core of the pellet where ablation acura. In order that full use be asde of the advanteges of the convergting churacter of the 1mploston, the ebletion pressure the surface of the high denalty core wate buffictentIy spherteslly symeter. This, in turn, places symecty requiresenta on the irrodietion of the outer ourface of the pellet. To enelyze these requirewents. as vell as so ontlelpate some hydzodynamlc tasebllicy problems which cen occur durtig imploslons, we heve developed a Inear perturbation methoo and have applied lt to representative laser detuen toplostons.

\section{PERTURBATION EQUATIONS}

The unperturbed, or zero order, flow is a purely rodial, ongle Independent flow. The method. though constructed to work in concert ulth seroorder Lagrangian camputetions, Is fundamencally Eulerten in the sense thet first order quentities are defined te zero order positions, l.e., on unperturbed trajectortes. It is, however, uneful to introduce the perturbed displecement, $\bar{\xi}$, defined through

$$
\frac{d \bar{z}}{d t}-(\overline{5} \cdot \bar{v}) \bar{v}_{0}=\bar{v}_{1}
$$

where $\vec{v}_{0}(\vec{r}, t)$ and $\vec{v}_{1}(\vec{r}, t)$ ore zero and firse order velocity, respectively. Linestizing Eulez's equation with respect to presaure, density. and velocity Rives

$$
\frac{d v_{1}}{d t}+\left(\vec{v}_{1} \cdot \bar{v}\right) \bar{v}_{0}=-\frac{\partial_{2}}{i_{0}} \frac{d \bar{v}_{0}}{d t}-\frac{\bar{j}_{p_{1}}}{\sigma_{0}}=\frac{i_{1}}{(2)}
$$


The perturbed density is then

$$
p_{1}=-\bar{\xi} \cdot \bar{\nabla}_{\rho}-p_{0} \bar{\nabla} \cdot \ddot{\xi}+\frac{\rho_{0}}{\rho_{o I}} p_{1 I} \equiv p_{1 C}+p_{1 L},
$$

and perturbed pressure, temperature, and other auxiliary state variables are given by expressions of the form

$p_{1}=-\bar{\xi} \cdot \bar{\nabla}_{p_{0}}+\rho_{1 L}\left(\frac{\partial p}{\partial p}\right)_{8}+s_{1 L}\left(\frac{\partial p}{\partial S}\right)_{\rho} \equiv p_{1 C}+p_{1 L}$

$T_{1}=-\bar{\xi} \cdot \bar{\nabla} T_{0}+o_{1 L}\left(\frac{\partial T}{\partial \rho}\right)_{s}+s_{1 T}\left(\frac{\partial T}{\partial s}\right)_{0} \equiv T_{1 C}+T_{1 L}$

where $I, C$, and $L$ denote initial, convective, and local ports, respectively. The specific entropy, $s$, and the density, $o$, are taken to be the independent state variables. The local entropy, $s_{1 L}$, is then advanced according to

$$
\frac{d S_{1 L}}{d t}=\frac{1}{\rho_{0} T_{0}}\left[\frac{d Q_{1}}{d t}-\left(\frac{\rho_{1 L}}{\rho_{0}}+\frac{T_{1 I}}{T_{0}}\right) \frac{d Q_{0}}{d t}\right]
$$

where $Q_{1}$ 1s obtalned from the perturbed viacous diesipation, external heat sources, and heat flow, the last being described by

$$
\frac{d Q_{1 K}}{d t}=\tilde{\nabla} \cdot\left(K_{1} \bar{\nabla} T_{0}+K_{0} \bar{\nabla} T_{1}\right) .
$$

The Landahoff-spitzer ${ }^{3} K$ and the Ideal ges equation of state are used in the calculations below.

When all first order quantities are asoumed to have the form $o_{1}(\bar{r}, t)=o_{1}(r, t) Y_{\ell, m}(\rho), E q .2 \mathrm{can}$, after some integrating, be put in the form

$$
\begin{aligned}
& \frac{d A}{d t}=a_{1} /\left(\frac{d r_{I}}{d r}\right) \cdot v_{r 1}=\left(\frac{d r_{I}}{d r}\right)_{h} \\
& \frac{d B}{d t}=\left(\frac{d r_{I}}{d r}\right)^{2} A, S_{T}=B /\left(\frac{d r_{I}}{d r}\right) \\
& \frac{d f}{d t}=\ell(\ell+1) p_{1} / o_{0}, c=\tau^{2}\left(\bar{\nabla} \cdot \bar{v}_{1}\right)_{\Omega} \\
& \frac{d D}{d t}=c / r^{2}, D=(\theta \cdot \xi)_{\Omega},
\end{aligned}
$$

Eq. 6 becomes

$\frac{d Q_{1 \kappa}}{d t}=\frac{1}{r^{2}} \frac{\partial}{\partial r}\left[r^{2}\left(\kappa_{1} \frac{\partial T_{0}}{\partial r}+\kappa_{0} \frac{\partial T_{1}}{\partial r}\right)\right]-\frac{\kappa_{0}}{r^{2}} \ell(\ell+1) T_{1}$,

and Egs. 3, 4, and 5 are unchanged except that nout al1 first order quantities are coeffictents of a particular $Y_{L}^{m}(\Omega)$. We have found, cherefore, that if the viscosity and theimal conductivity are scalar, the equations of motion for different $\ell^{\prime} s$ decouple and ere degenerste with respect to $\mathrm{m}$, with obvious Important advantages for corputation and interpretation. ${ }^{4,5,6}$ A three-dimensional onalyst.s, not twodimenolonal as in $(r, z)$ hydro-codes, is obtalned with about the complexity and computational cost of - one-dimensional calculation. The scalar assumption requires that we be justifled in ignoring thermoelectric effects and off-diagonal viscous stress tenser elements, assumpions which seem reasonable In many cases of interest. It is noteworthy that taking only the angular thermal relaxation term from $\mathrm{Eq} .8$ and the assumed form $T_{1} \sim \epsilon^{-\tau / \tau}$ gfves an angular symetriaing time

$\tau=\frac{3}{2} \frac{k\left(n_{e}+n_{1}\right) r^{2}}{l(l+1) k_{0}}=\frac{3.2 \times 10^{-10}\left(n_{e}+n_{1}\right) r^{2} \& \Lambda_{e 1}}{T(e v)^{5 / 2} \ell(l+1)}$

which can be as ame 11 as $10^{-12} \mathrm{sec} / \ell(t+1)$ for scre situarions which arise in loser fusion work. A computer code has been written which integrates the above equetions self consistently with the zero order equations.

\section{ABLATION PRESSURE SMMIETRY}

In this letter the equations derived above are used to show the feportant result thac electron thermal conduction in angular directions can have a very powerful effect in makling ablation surface pregsure6, and thus implosions, wuch wore symetrical than the deposition of laser energy at the critical surface. Whether a pellet starts as a sphere or she11, ablation preasure formg a shell of highez than Initial density and sowewhat smallez thiciness than radius, jugt inside the ablation surface. If the pressure 19 assyaeric. then parts of this shell w11 reach the center ahead of others and way prevent the achievement of the necenary high densitses. It 10 then neceasary that the distortion, ${ }^{b}, f$ ' 


$$
\delta_{\mathrm{R}, \ell} \equiv \frac{\int_{0}^{t_{f 1 n a l}} d t v_{r 1, \ell}\left(r_{s}\right)}{\int_{0}^{t_{f I n e l}} d t v_{r o}\left(r_{s}\right)} \approx \frac{1}{r_{s I}} \int_{0}^{r_{s I}} \frac{v_{r 1}, L\left(r_{s}\right)}{v_{r o}\left(r_{s}\right)},
$$

be suffictently small for all $\ell$-numbers. The $d r$ integracion is in the sense that $d t=d r_{s} / v_{r o}\left(r_{s}\right)$ and $r_{\theta}$ is the instunianeous radius of the shell. The distortion represents the ratio of the perturbed motion of the shell to the intital shell radius, $r_{s} t^{*}$ The ollowed distortions may be as ierge as 0.1 for pellets (spheres or she11s) which are nct to be ton highly compressed. But for shells of large aspect ratio (radius to thickness) they must be wuch sma11er. It 19 Impossible to be more prectse without considering cases individually, but it will be clear that Important general conclusions can be reached from $s \operatorname{lmply}$ requiring $\delta_{R} \leqslant 0.1$.

An 1mpulse approximation is na applled in which varfous idealized sets of $p_{0}(r), T_{0}(r)$ profiles of Deuterfum-Tritium mixtures are assumed and held fixed in time, on the grounds that they do not change significantly during the time of interest for the required flrst-order calculations. (Calculations wth self consistent zero order flows have shown the important additional result that the ablation process is itself positively stable.;

The four zezo order cases used here are the two forms, I and II in Fig. 1, w with two different

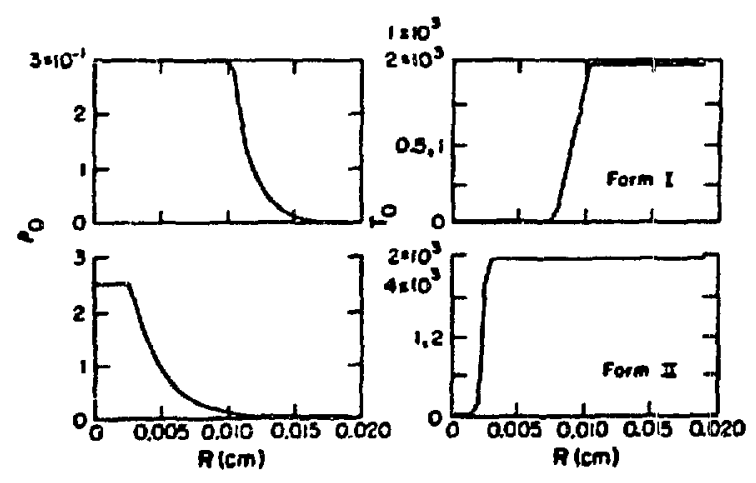

Fig. I. Zero order density, temerature prefiles. Mote two temperature scules for each form.

The unfeg throughout are c.g.s.; temperetures ar: In ev. temperature scales each. In both $r_{\text {crit }}=2 \times 10^{-2}$ $\mathrm{cm}$ (where $o_{\text {crit }}=5 \times 10^{-3} \mathrm{~g} / \mathrm{cm}^{-3}$ ). In I the ratio of ablation to critical surface radil is seen to be two, typlcsl of earlier times; in II the ratio is elght. These density profiles hove filled centers but are thought of for present purposes, which do not directly involve the center, as representing - variety of more or less hollow profiles. The temperature is then given the same initial perturbation, $T_{1}(r, t=0)$, localized near $r_{c r l t}$ for all $l$. This perturbation corresponds for $l=0$ to an Increment of the zero order sbsorbed energy and for $\ell>0$ to an asymetry of the absorbed energy which is equal in amplitude, $i . e .$, where the $\mathrm{Y}_{\ell}^{m}(\Omega) \cdot \mathrm{\prime}=$ \pm 1 , to the $l=0$ increment. The contribution of the absorbed energy input asymetry at the time represented by the chosen $p_{0}, T_{0}$ profiles to the asymmetry of the system at a given $\ell$ can be estimated by taking the ratio of the $\ell(0)$ and $l=0$ Iinear responses of the system for the given $I_{1}(r, t=0$ ) to be the asymetry resulting from $100 \%$ input asymmetry at that $l$. In particular the ratio $v_{r 1, \ell} / v_{\text {ro }}$ In Eq. 10 is taken tu be the value of $v_{r 1, \ell} / v_{r 1,0}$ at the she11, obtained after the impulse contributions of $T_{1}(r, t=0)$ to the ablation driven implosion has occurred. The asymetry caused by smaller input modulations is then scaled down from this value. Note that $Y_{\mathcal{L}}^{\mathbb{D}}(\Omega)$ has 2 ar more maxima, depending on $m$, which mey indicate the cortespondence to the number of Incident beams.

A large muber of overlapping focal spots may give quite small ebsorbed energy rodulation, dependling on the spot size and nonnormal absorption efficlency. However, as the number of beams and dow. Inont $\ell$ number are reduced to four or less, it will be difficult to reduce the modulation very much below 507 whthout the equivelent of rather unconventonel optics.

Flgures 2 and 3 show $l=0$ and 4 responses of the Form II, $T_{0} \max =2 \mathrm{keV}$, profiles to the $T_{1}\left(r_{1} t=0\right)$ shewn In Fig, 1. Figure 2 shows themal weve propegeting rapidiy lmward, giving increasing $\rho_{1}$ as it revehes regions of larger $\rho_{0}$, and cousing only a 11 acoustic response unt 11 tt reaches the ablation front and wakes $1 t^{\prime} s$ contributon to oblation by launching strong ocoustic wevea Inward (10plosion) and outward (blow-off recol1), -t sbout $t=4.0 \times 10^{-11} \mathrm{sec}$. The $\ell=4$ 


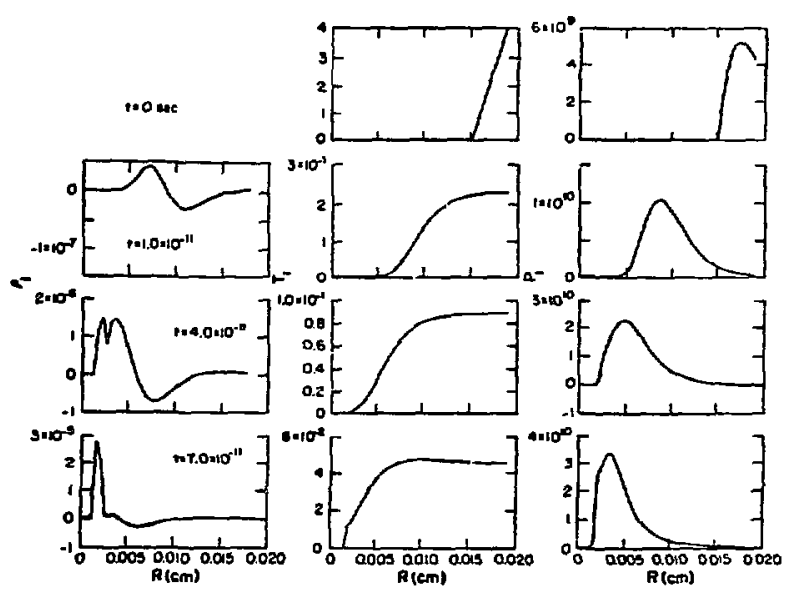

Fig. 2. Time sequences of first order quentities irom Form II, $2 \mathrm{keV}, l=0$ celculation.

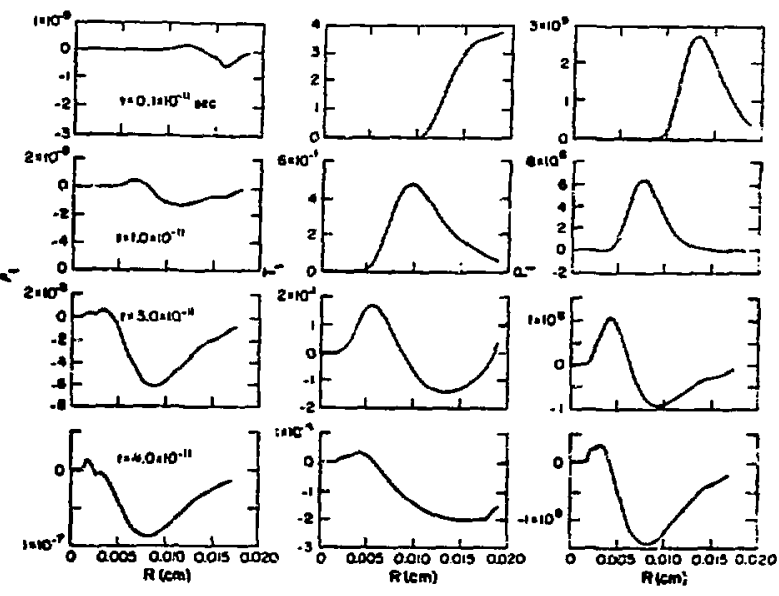

Fig. 3. Time sequences of first order quantities from Form II, $2 \mathrm{keV}, \ell=4$ calculation.

response, Fig. 3, shows the thermal and pressure wave beling attenuated very strongly by angular thermel conduction, and to some extent by the angular coustic reaponse, the cause of large negative $T_{1}$ 's and $p_{1}^{\prime}$ being mostly ecoustic. Figures 4 and 5 show the maxtwo over $r$ of the $P_{1}(r)$ and ${ }{ }_{r 1}(r)^{\prime} \cdot s$ - function of time for 11 four zero order profiles and assorted $\ell ' s$. Figure 6 shows the history of posttione of these negative maxime of the $v_{1 r}(r)$ 's for $l=0$ (the $l>0$ curves are quite siatlar) from wilch one can see when the thermal wave reaches the ablation front and makes its essentialiy Impulsive contribution to $v_{I l}$ of the shell.

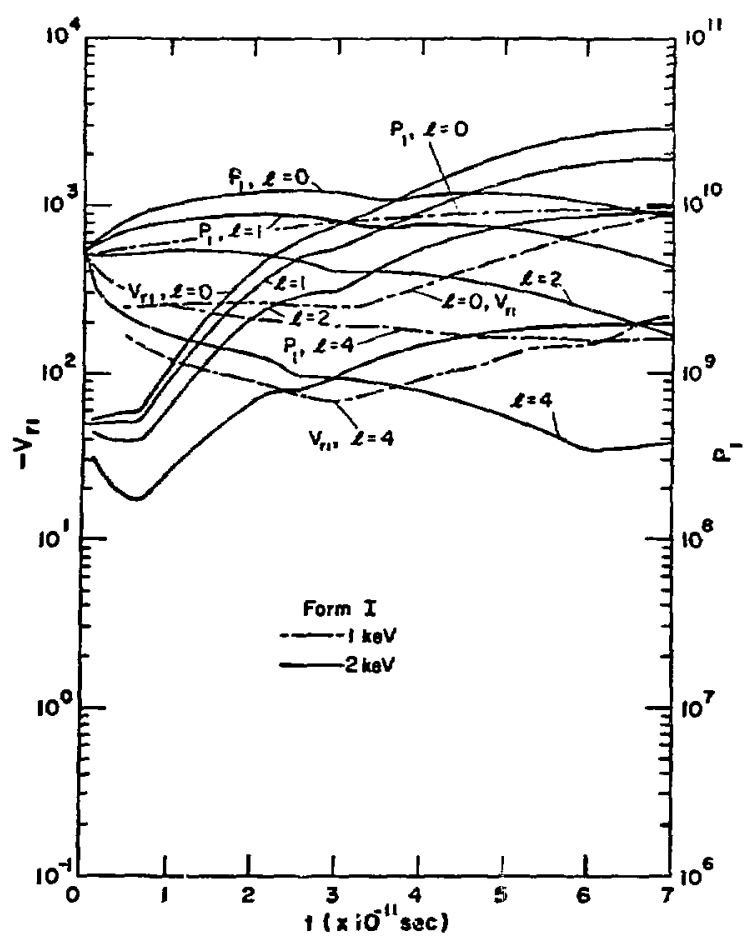
Fig. 4. Time histories of $p$, and $v_{r 1}$ maxima for
Forin I calculations.

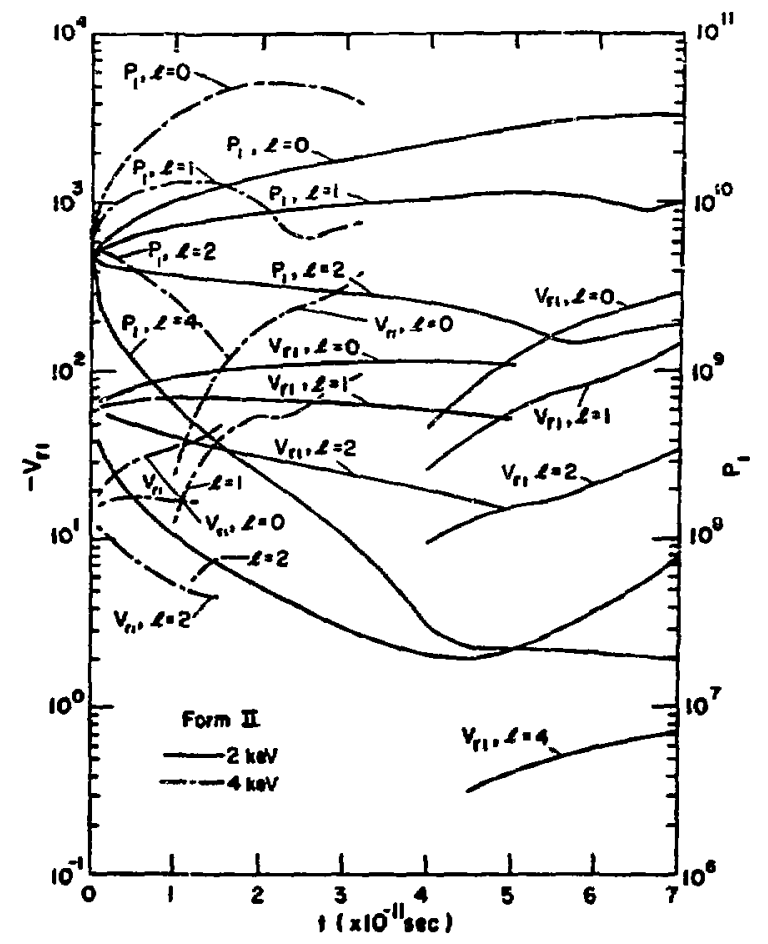

Fig. 5. Time hiatortes of $p$, and $v_{x l}$ marima for Form II calculations. 


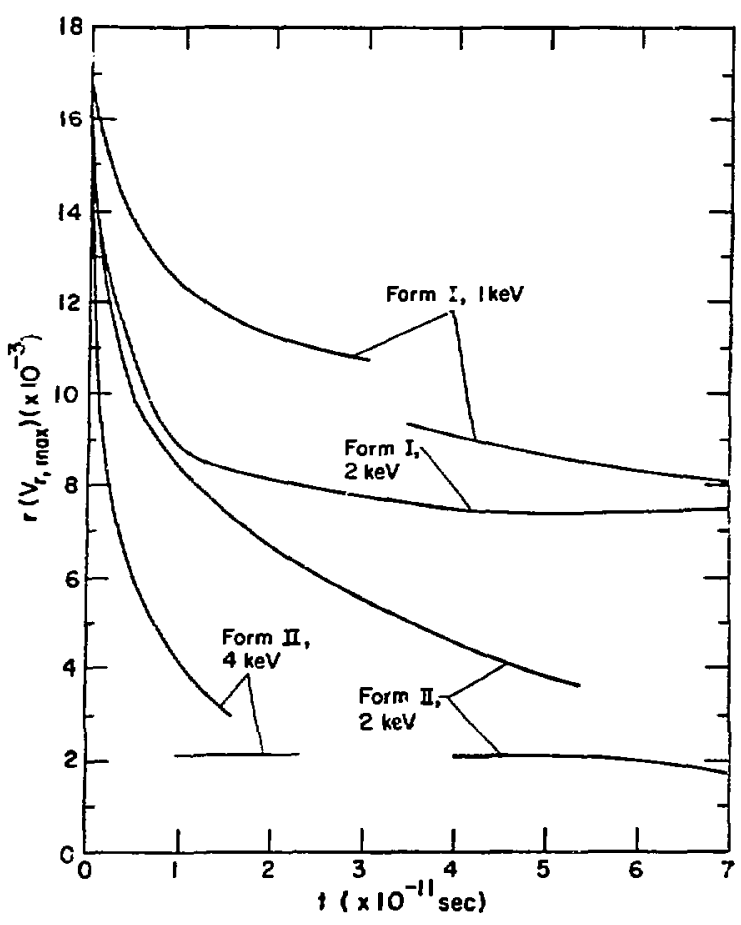

Fig. 6. Histories of radial positions of $v$ mexima from $l=0$ calculations; $l>0$ positions are very similar.

From Figs. 4,5 and 6 one can see a genaral iriprovement in implosion symetry in going to higher temperatures and larger ratios of ablation to critIcal surface radil, both associated with latter times in a given implosion. The improvement with increasing critlcal radius also atrongly favors larger laser light wavelengths.

More particularly it is seen from $\Gamma \mathrm{ig} .4$ that energy absorption with $100 \%$ angular modulation is suffictently smoothed by thermal conduction at early implosion times to give a contribution to the dr integration in Eq. 10 of 0.1 or less, only if $\ell=4$ or larger, whereas at later times and higher temperatures Fig. $5, \ell=2$ aymetry is sufíclent if not $\ell=1$. Morecver, $L=1$ perturbations are not in all cases disruptive since they may only shift the implosion canter. Hence, within the limitations of this perturbation treatment and impulse approximation, we conclude that whlle the equivalent of four or more evenly spaced beans may be required to initiate an adequately symetric imploston, the subsequent, and more intense, irradiation may be carried by as few as one beam.

\section{REFERENCES}

1. J. Nuckolls, L. Wood, A. Thlessen, and G. Zfmermen, Nature (London) 239, 139 (1972).

2. J. S. Clarke, H. N. Fisher and R. J. Mason, Phys. Rev. Lett. 30, 89 (1973), and 30,249 (1973).

3. Rolf Landshoff, Transport Phenomena in a Mixture of Electrons and Nucle1, Los Alamos Report IA334, July 23, 194;5 (Reclassified Feb. 1962) (this is the earliest definitive work on electron therme1 conduction); Phys. Rev. 76, 904 (1949); Phys. Rev. 82, 442 (1951); L. SpItzer, Physice of Fully Ionized Ceses (Interscience, New York, 1956), Chap. V.

4. This method and preliminary results showing Taylor Instabilities of time dependent zero order implosions rere first presented to the laser fusion community at the January 4-5, 1973 AEC Laser Fusion Coordinating Committee Meting at LLL, and appear in various internal LASL reports in November and December 1972.

5. The results given here were first presented at the Washington, D. C. APS Meeting, D. B. Henderson and K. L. Morse, Bull. Am. Phys. Soc. Ser. II. 18, 684 (1973).

6. This report is the text of talks to be presented at the Philadelphia APS Meeting, D. B. Henderion and R. L. Morse, Bull. Am. Phys. Soc. Ser. II 18,1360 (1973) and R. L. Morse, Bull. Am. Phys. Soc. Ser. II. 18, 1359 (1973). 